\title{
SNAGGED SETAE: EVALUATING ALTERNATIVES TO COTTON WOOL BUNGS FOR LIQUID-STORED SPECIMENS
}

\author{
Lu Allington-Jones ${ }^{1}$ and Emma Sherlock ${ }^{2}$ \\ ${ }^{1}$ The Conservation Centre, Department of Science Facilities, The Natural History Museum, Cromwell Road, \\ London, UK \\ l.allington-jones@nhm.ac.uk \\ ${ }^{2}$ Department of Life Science, The Natural History Museum, Cromwell Road, London, UK \\ e.sherlock@nhm.ac.uk
}

\begin{abstract}
This study comprises a search for a replacement for cotton wool (also called cotton batting) stoppers within spirit collections. It briefly explores relevant published literature and documents a three-year experiment to test the durability of plastic lids, inert foam, and parafilm, within ethanol, IDA, and formalin. Following visual observations and Fourier transform infrared spectroscopy the study concludes that Parafilm $\mathrm{M}^{\mathrm{TM}}$ is unsuitable for long-term use but Plastazote ${ }^{\circledR}$ bungs and polyethylene lids are suitable for vials within glass-lidded jars. The study should aid curators making decisions regarding suitable storage and transportation of spirit collections and prevent future damage of delicate specimens.
\end{abstract}

\section{INTRODUCTION}

The Department of Zoology at the Natural History Museum (London, UK) (NHM) holds an estimated 22 million spirit-stored specimens housed in approximately 450,000 jars. The air conditioning system within the storage area aims to maintain the spirit collection at $14 \pm 1{ }^{\circ} \mathrm{C}$ to slow biodeterioration and reduce the risk from fire. The majority of specimens are preserved in $100 \%$ ethanol (ethyl alcohol $\mathrm{C}_{2} \mathrm{H}_{6} \mathrm{O}$ ), $80 \%$ industrial denatured alcohol in water (IDA — ethanol with unpalatable additives), or formaldehyde $4 \%$ aqueous solution ( $10 \%$ formaline solution) buffered $(\mathrm{pH} 7.0 \pm 0.2)$. The choice in preservative depends on the specimen type. Some materials, such as feather keratin, are more stable in formaldehyde solutions than in ethanol (von Endt et al. 2000), and formalin generally has better color preservation (de Moor 1990). Specimens stored in high percentages of ethanol dehydrate and can become brittle (de Moor 1990). There is disagreement whether DNA can successfully be extracted from specimens stored in formalin, however, and absolute ethanol is the preferred medium for such samples (Crisculo 1992, Vachot and Monnerot 1996, Barnes et al. 2000, Rodríguez et al. 2002). Simmons (1995) provides a more detailed discussion of the huge variety of fluid preservatives used by museums over the last 300 years. At the NHM cost is also a factor: Many specimens are stored in IDA because it is cheaper than pure ethanol. Small specimens within the collection are stored within glass vials inside a glass jar with a ground glass stopper. The glass vials are either stoppered with cotton wool or by a polyethylene cap, neither of which is entirely satisfactory. Clark (1992) recommended toughened borosilicate glass jars with ground glass stoppers as the most suitable containers for spirit collections, and this view has been almost universally accepted. For internal vials within these jars, however, the search continues.

Cotton wool plugs (also called cotton batting plugs) have been used extensively in the invertebrate collections at the Natural History Museum for stoppering vials. It has been brought to the curators' attention over the years, however, that specimens are either getting lost within the fibers of the cotton wool if very small, or more commonly, specimens with setae or other protrusions are becoming damaged while getting entangled. The Annelid curator, after finding a damaged specimen within cotton wool, decided to 


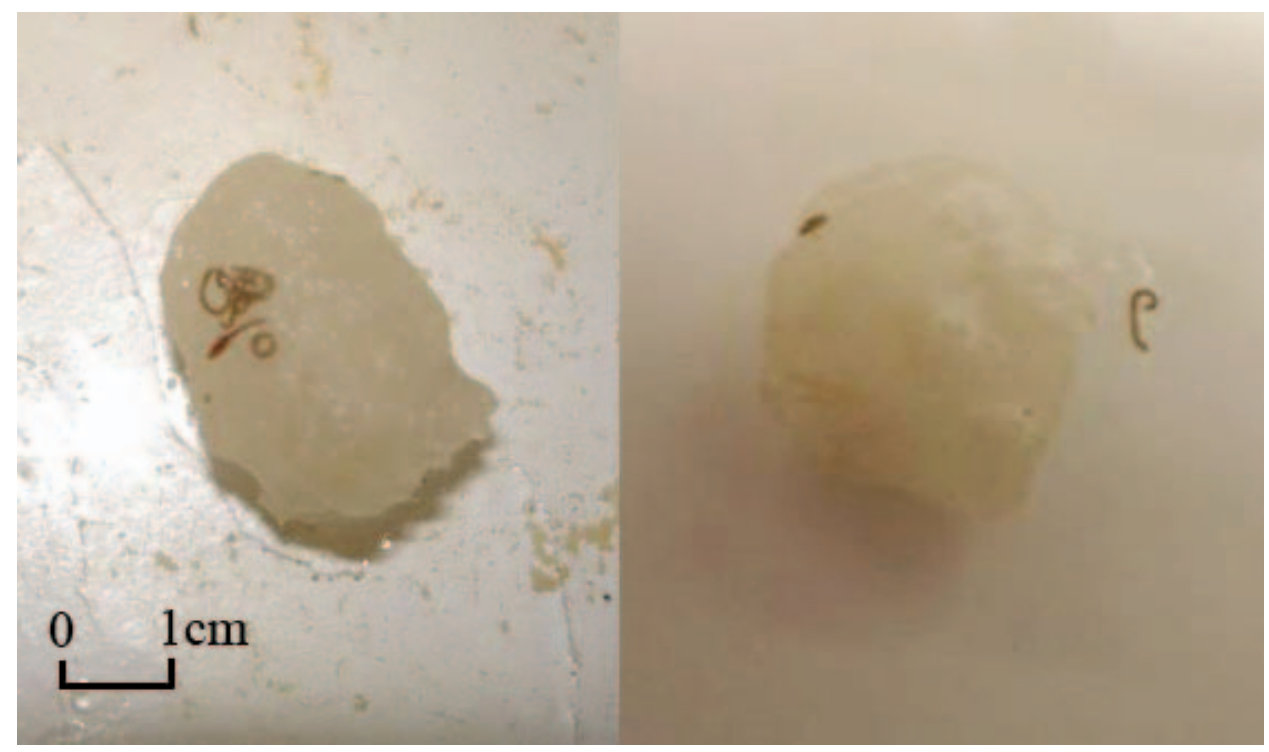

Figure 1. (a) Small specimens embedded in a cotton wool bung. (b) Specimens teased out of the cotton wool are found to have fibers caught on their setae.

replace all of this type of bung within the collection to prevent this occurring again but was unsure as to the best replacement material. The obvious choice would be the polyolefin bungs the Museum vials are supplied with; however, some plastics have been proven previously not to be a suitable storage media in certain circumstances in Museum collections (Clark 1992), and therefore this required thorough testing. For example, many lids within the spirit collections are Bakelite ${ }^{\circledR}$. This is prone to embrittlement, exacerbated by formaldehyde vapor, and can unscrew as temperature fluctuates (Simmons 1995). Suzumoto (1992) also notes that Bakelite is embrittled by alcoholic solutions and possesses lower initial flexibility than polypropylene.

A material used to replace, or cover, cotton wool bungs must be stable in formalin, ethanol, and IDA. It must also not affect the $\mathrm{pH}$ of the preservative, since alkalinity causes leaching of lipids and proteins from specimens (von Endt et al. 2000), and at below pH 6.5 protein embrittlement, decalcification, hardening, and color loss occurs (Van Dam 2000, Kotrbai and Golbig 2009). This project aims to evaluate the suitability of Plastazote ${ }^{\circledR}$ bungs, polyethylene caps, and Parafilm $\mathrm{M}^{\mathrm{TM}}$ wraps as replacements for cotton wool bungs for small vials within glass jars.

\section{Alternative Stoppers}

\section{Fiber Bungs}

Cotton wool is used at the NHM for stoppering small vials, and Simmons (1995) recommends the use of polyester fiber bungs for the same purpose. Cotton wool is no longer considered the sole inducer of Byne's disease (von Endt 1996), but it has been found to react with formaldehyde (Kamath et al. 1985). Cotton wool is still recommended within taxidermy (Dickinson 2008) but has long been recognized as an unsuitable packing material for highly ornamented or delicate natural history specimens for physical reasons (Rixon 1976). Fiber bungs become snagged on fine structures on specimens, such as worm setae (Fig. 1), risking damage when it is 
disentangled. It has been suggested that fiber bungs can be wrapped in Parafilm $M$ to prevent snagging.

\section{Polyolefin Lids}

Polypropylene and polyethylene are "not totally impervious to organic solvents. Although the rate of attack is slow and greatly reduced at low temperatures" (De Moor 1990). Some polyolefins, however, are prone to shattering at low temperatures (Baker 1995). Polyolefins are highly solvent resistant compared with other synthetic polymers (Baker 1995) and are usually considered safe for museum storage solutions (von Endt et al. 1995) and spirit containers (Baker 1995, Fenn 1999). Polyethylene and polypropylene lids have, however, been observed to lose flexibility and eventually snap (Lincoln 1989). Snapping of lids purchased in the late 1970s has also been observed within the zoology spirit collection at the NHM. When specimens are transferred to the laboratories for study, or are loaned to other institutions, the temperature differences cause pressure changes within the vials. Van Dam (2000) cites such pressure changes, due to the differences in expansion coefficients between air, glass, and the preservative, as the cause of cracking of embrittled plastic lids. Continued reopening for research or respiriting is presumably also a factor. Light energy has also been cited as causing deterioration of polyolefins (Chanda and Roy 2006). Polyethylenes are less susceptible to degradation by ultraviolet light than polypropylenes, and high-density polyethylene (HDPE) generally possesses higher resistance to oils and organic solvents (Baker 1995). Van Dam (2000) found that HDPE, which is also less permeable to oxygen and vapor transfer, retained flexibility for longer than low-density forms and polypropylene. Reilly (1989) suggests protecting the lids with a barrier of Parafilm $M$ so that they are not in contact with vapors from the preservative. Suzumoto (1992) recommends a polypropylene lid with a polyethylene insert.

\section{Polyolefin Foam}

Polyolefins are not thought to produce damaging degradation products (Baker 1995), and the substitution of a rigid lid with a foam form could resolve some of the aforesaid issues. Gisbert and Garcia-Perea (1992) recommended the use of polyethylene foam rings to support jars within ethyl alcohol and other fluids. Callomon (2012), however, discovered failure of compressed polyethylene foam lid liners after 12 years in ethanol. Williams (2012) proposed that the polyethylene had oxidized and underwent stress cracking under the influence of ethanol. It must be noted, however, that polyethylene products vary greatly between product type and manufacturer regarding grade and chemical composition (Neumann 2012, Williams 2012). Individual foams must therefore be tested, and no generalizations can be made.

Plastazote, widely used as a storage material at the NHM, is a nitrogen-expanded closed cell cross-linked polyethylene foam created by Zotefoams. Black and white colors have been cleared for food contact and use with water for human consumption (TIS 20). Black, white, and gray Plastazote have also passed accelerated aging tests performed by the Conservation Centre at the NHM. The nitrogen-foaming agent used in the manufacture of Plastazote does not remain within the foam, and the cross-linked nature ensures higher resistance to solvents (Baker 1995). Plastazote stored with zoological specimens in IDA and ethanol at the NHM since the 1960s appears chemically stable and structurally sound. 


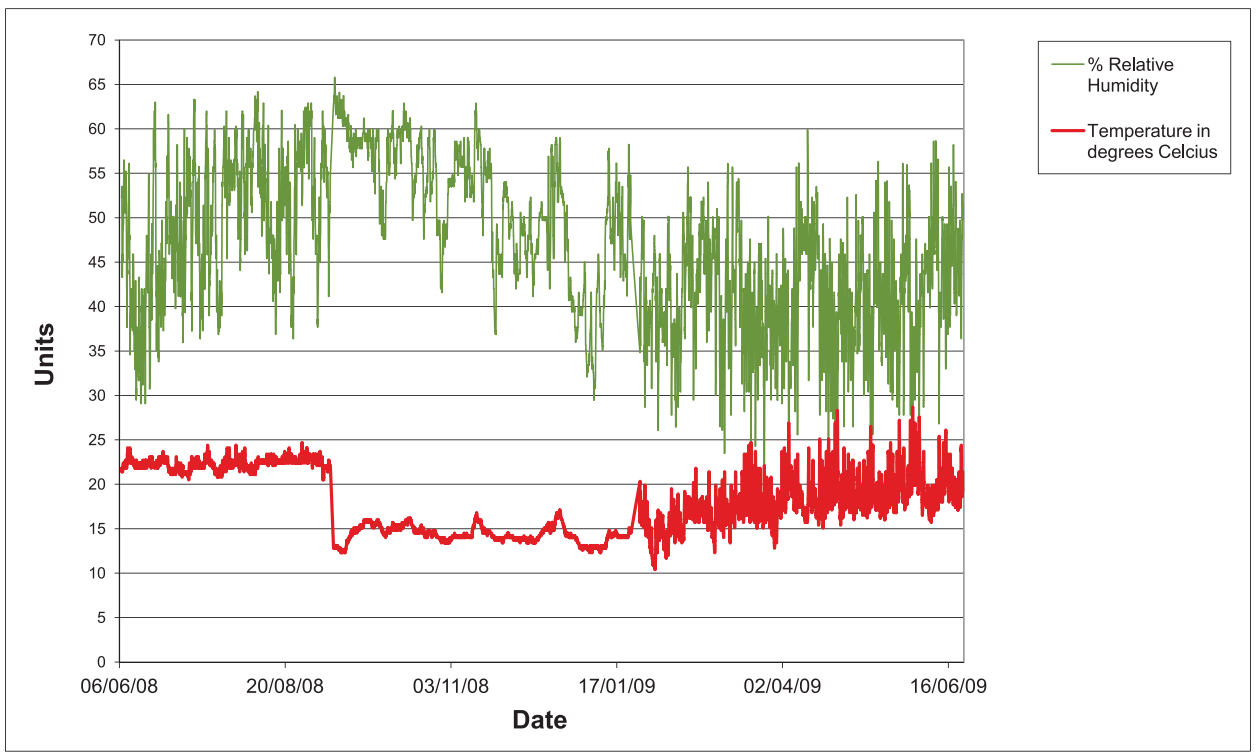

Figure 2. An example of the annual cycle of the environmental conditions undergone by the samples. From June to September 2008 the samples were stored in a large working laboratory and then moved to the cold storage area. In February 2009 they were moved to a different laboratory.

\section{Methodology}

HDPE caps (SAMCO Durham tube caps by S Murray \& Co), Plastazote $\left(1 \mathrm{~cm}^{3}\right.$ white LD45), cubes and Parafilm M samples were left dry or immersed in either formalin, IDA, or ethanol within glass jars. The jars were sealed with soft white paraffin-coated ground glass stoppers. The samples were subjected to 4- to 6-month cycles of alternating storage within two department laboratories and the cold storage area, to simulate conditions experienced by frequently studied specimens. Temperature and humidity of the storage and laboratory areas were measured using a Tinytag Ultra TGU-1500 (by Gemini Dataloggers), and equivalent luminous exposure (ELE) was extrapolated using Lightcheck ${ }^{\circledR}$ Ultra. Figure 2 shows the typical environmental conditions of a single annual cycle. Light was absent within cold storage, but within the laboratory ELE was 44,350 lux hours per month.

After 36 months observations were made by eye and at $400 \times$ magnification of the samples and compared with the dry-stored control samples. Then $25 \mathrm{ml}$ samples of the preservation fluids were reduced by evaporation to $5 \mathrm{ml}$ and a droplet analyzed using a Perkin Elmer AutoIMAGE FT-IR microscope and diamond anvil (two diamonds each set in a metal holder), the spectrograph averaged over 32 frames. No clear spectra were obtained. Initial attempts to analyze droplets of the samples on potassium bromide tablets with a Perkin Elmer SpectrumOne FTIR Spectrometer failed due to interference planes created by dissolution and recrystallization, even when the tablets were crushed and reformed. Successful FTIR spectrographs were then created using a Perkin Elmer SpectrumOne FTIR Spectrometer from potassium bromide tablets containing the dry residue of $100 \mathrm{ml}$ evaporated samples. Acidity of the solutions was tested using both Whatman and Fluka universal indicator paper. 


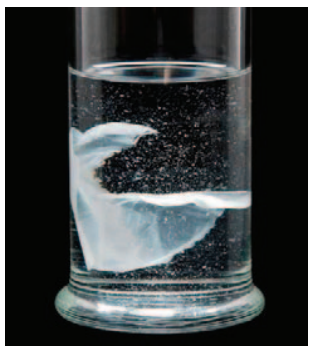

Figure 3. Photograph of the particles visible within one of the jars of $100 \%$ ethanol and parafilm, after 36 months.

\section{RESULTS}

Evidence of deterioration of Parafilm $M$ within the three liquids was seen as disassociated particles plus a thinning and perforation of film edges (Fig. 3). The film edge within the ethanol also showed darkening in places. Deterioration of the parafilm in the ethanol solution was also detected using Fourier transform infrared (FTIR) analysis (Fig. 4). Although the FTIR spectra could result from contamination from soft white paraffin from the jar seals, it must be noted that these results were obtained for all of the Parafilm $\mathrm{M}$ tests but not for any of the other materials, and that Parafilm M also showed visual signs of deterioration. No deterioration to the polyethylene cap or plastazote was observed by eye or microscopical analysis or detectable through FTIR spectroscopy. Plastazote stored alongside specimens within 80\% IDA since the 1960s was also inspected at $400 \times$ magnification, and no signs of cell wall failure, dissolution, or swelling were observed. Similar results have been found within the Jefferson Collection at the National Museum and Gallery of Wales, where plastazote bungs have been stored for 17 years in ethanol since a conservation project in 1996 (Carter 1998). The $\mathrm{pH}$ of all liquids were

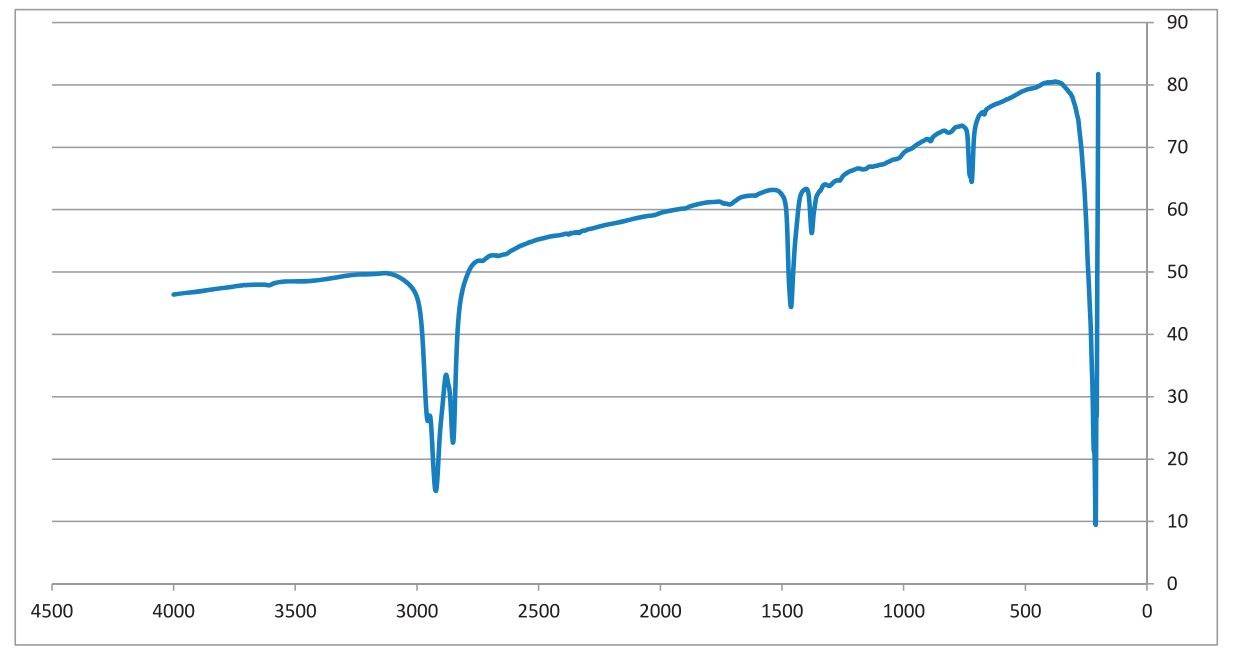

Figure 4. FTIR Spectrograph of the residue left by evaporating $100 \mathrm{ml}$ of ethanol that had contained Parafilm for 36 months. The distinct peaks occurring at 2,922, 2,851, 1,463, 1,377, and $720 \mathrm{~cm}^{-1}$, and the lack of minor peaks between 500 and $2,000 \mathrm{~cm}^{-1}$, are characteristic of Parafilm. 


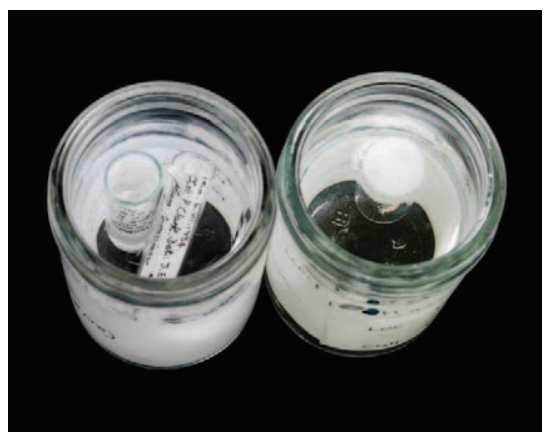

Figure 5. Small glass vials with Plastazote bungs should be inverted within the larger jar to reduce the risk of evaporation due to buoyancy.

unaffected by the presence of the plastic samples (IDA and formaldehyde $4 \%$ aqueous solution at $\mathrm{pH} 7$ and ethanol at $\mathrm{pH}$ 7.5).

\section{Conclusions}

Parafilm $\mathrm{M}$ is not stable in preservation fluids and should not be used to cover cotton wool bungs or to form a barrier for polyolefin lids. Plastazote is stable and does not snag on delicate structures of specimens. It may be used as bungs for glass vials within ethanol, IDA, and formlin within larger glass jars. Because of the buoyancy of plastazote, the vials should be inverted (Fig. 5). It is unfortunate that compression-related issues were not taken into account at the start of the experiment, although the compression forces experienced by a bung are far less than those suffered by a lid gasket. Although no contamination of the storage liquids was observed from the lids, many years of observational evidence regarding cracking cannot be ignored. The loss of flexibility of polyolefins is still an issue. Loss of flexibility within a foam is less of a physical problem than loss of flexibility within a lid, although embrittlement and fracture of cell walls will lead to structural collapse, which can cause leaking. This is why foam bungs should only be used for vials within a larger jar which itself possesses a glass stopper. It must also be noted that replacement of a failed foam bung is much cheaper than replacement of a plastic lid. Plastazote bungs can be carved using a cork borer or ordered in large quantities from Ramplas (Ram Cellular Products Ltd).

HDPE caps should be used when transporting individual vials on loan to other institutions. Vials should be filled to a maximum $90 \%$ of its volume when using ethanol and $95 \%$ when using water-based preservation fluids as recommended by Van Dam (2000) to prevent them popping off due to temperature changes causing expansion. Contraction within the vials should be accommodated by the flexibility of caps which have not been embrittled by long-term storage in preservation fluids.

\section{FURTHER WORK}

The samples will be retested after another 36 months to determine any further changes. A new set of samples should be created to test the stability of Plastazote in other preservation fluids, and its durability under prolonged compression.

\section{ACKNOWLEDGMENTS}

The authors would like to thank Hazel Hunter, Chris Jones, Andrew Cabrinovic, Chris Collins, and Miranda Lowe at the Natural History Museum (London, UK), as well as the editor and reviewers. 


\section{Literature Cited}

Baker, M.T. 1995. Synthetic polymers. Pp. 305-323 in Storage of Natural History Collections: A Preventive Conservation Approach (C.L. Rose, C.A. Hawkes, and H.H. Genoways, eds.). SPNHC, Iowa City. 448 pp.

Barnes, I., J. Holton, D. Vaira, M. Spigelman, and M.G. Thomas. 2000. An assessment of the long-term preservation of the DNA of bacterial pathogen in ethanol-preserved archival material. Journal of Pathology 192:554-559.

Callomon, P. 2012. NH-COLL listserver. http://mailman.yale.edu/mailman/listinfo/nhcoll-1 (7 August 2012).

Carter, J. 1998. The Jefferson collection of invertebrate animals: A zoological conservation project. The Conservator 22:36-43.

Chanda, M. and S.K. Roy. 2006. Plastic Technology Handbook, $4^{\text {th }}$ ed. CRC Press, New York. 896 pp.

Clark, P. 1992. Ground glass stoppered jars for fluid collections. Pp. 221-223 in Storage of Natural History Collections: Ideas and Practical Solutions (C.L. Rose and A.R. de Torres, eds.). SPNHC, York, xvi + 346 pp.

Crisculo, G. 1992. Extraction and amplification of DNA from wet museum collections. Ancient DNA News $1: 12-13$.

De Moor, F.C. 1990. Containers for wet collections-Problems and solutions. Pp. 27-36 in Natural History Collections: Their Management and Value (E.M. Herholdt, ed.). Transvaal Museum, Pretoria. 172 pp.

Dickinson, J. 2008. Practical demonstration: Preparing a small mammal study skin. Natsca News 14:16.

Fenn, J. 1999. Plastic materials used in the herbarium. Pp. 235-249 in Managing the Modern Herbarium: An Interdisciplinary Approach (D.A. Metsger and S.C. Byers, eds.). SPNHC, Vancouver, Canada. 384 pp.

Gisbert, J. and R. Garcia-Perea. 1992. Double-jar system for types in fluid collections. Pp. 225-226 in Storage of Natural History Collections: Ideas and Practical Solutions (C.L. Rose and A.R. de Torres, eds.). SPNHC, York. xvi +346 pp.

Kamath, Y.K., S.B. Hornby, and H.D. Weigmann. 1985. Irreversible chemisorption of formaldehyde on cotton cellulose. Textile Research Journal 55:663-666.

Kotrbai, M. and K. Golbig. 2009. A new approach to stabilize the $\mathrm{pH}$ in fluid-preserved natural history collections. Collection Forum 23(1-2):18-22.

Lincoln, R. 1989. Storage containers. Pp. 53-63 in Conservation of Natural History Specimens: Spirit Collections (C.V. Horie, ed.). Manchester Museum and Department of Environmental Biology, University of Manchester. 114 pp.

Neumann, D. 2012. NH-COLL listserver. http://mailman.yale.edu/mailman/listinfo/nhcoll-1 (7 August 2012).

Reilly, M. 1989. Curation of a small collection. Pp. 95-112 in Conservation of Natural History Specimens: Spirit Collections (C.V. Horie, ed.). Manchester Museum and Department of Environmental Biology, University of Manchester. $114 \mathrm{pp}$.

Rixon, A.E. 1976. Fossil Animal Remains: Their Preparation and Conservation. Athlone Press, London. 304 pp.

Rodríguez, D., R. Bastida, and P. Olsson. 2002. DNA extraction from formalin fixed Franciscana tissues. Latin America Journal of Aquatic Mammals, Special Issue 1(1):123-128.

Simmons, J.E. 1995. Storage in fluid preservatives. Pp. 161-186 in Storage of Natural History Collections: A Preventive Conservation Approach (C.L. Rose, C.A. Hawkes, and H.H. Genoways, eds.). SPNHC, Iowa. $448 \mathrm{pp}$.

Suzumoto, A.Y. 1992. Storage containers for fluid-preserved specimens. Pp. 217-220 in Storage of Natural History Collections: Ideas and Practical Solutions (C.L. Rose and A.R. de Torres, eds.). SPNHC, York. xvi $+346 \mathrm{pp}$.

Vachot, A.-M. and M. Monnerot. 1996. Extraction, amplification and sequencing of DNA from formalin-fixed specimens. Ancient Biomolecules 1:3-16.

Van Dam, A.J. 2000. The interactions of preservative fluid, specimen container, and sealant in a fluid collection. Collection Forum 14(1-2):76-92.

von Endt, D. 1996. Staying on the subject of efflorescence. Natural Sciences Conservation Group Newsletter 4:11.

von Endt, D.W., W.D. Erhardt, and W.R. Hopwood. 1995. Evaluating materials used for constructing storage cases. Pp. 269-282 in Storage of Natural History Collections: A Preventive Conservation Approach (C.L. Rose, C.A. Hawkes, and H.H. Genoways, eds.). SPNHC, Iowa. 448 pp.

von Endt, D.W., E.R. Yourd, and P.E. Hare. 2000. Spirit collections: Accelerated aging studies concerning the stability of keratin in ethanol and formalin. Collection Forum 14(1-2):66-75.

Williams, R.S. 2012. NH-COLL listserver. http://mailman.yale.edu/mailman/listinfo/nhcoll-1 (7 August 2012). 